\title{
Photodissociation Dynamics of the Ethoxy Radical Investigated by Photofragment Coincidence Imaging
}

\author{
Ann Elise Faulhaber, David E. Szpunar, Kathryn E. Kautzman, and Daniel M. Neumark* \\ Department of Chemistry, University of California, Berkeley, California 94720, and Chemical Sciences \\ Division, Lawrence Berkeley National Laboratory, Berkeley, California 94720
}

Received: June 14, 2005; In Final Form: August 24, 2005

The photodissociation dynamics of the ethoxy radical $\left(\mathrm{CH}_{3} \mathrm{CH}_{2} \mathrm{O}\right)$ have been studied at energies from 5.17 to $5.96 \mathrm{eV}$ using photofragment coincidence imaging. The upper state of the electronic transition excited at these energies is assigned to the $\tilde{\mathrm{C}}^{2} \mathrm{~A}^{\prime \prime}$ state on the basis of electronic structure calculations. Fragment mass distributions show two photodissociation channels, $\mathrm{OH}+\mathrm{C}_{2} \mathrm{H}_{4}$ and $\mathrm{CH}_{3}+\mathrm{CH}_{2} \mathrm{O}$. The presence of an additional photodissociation channel, identified as $\mathrm{D}+\mathrm{C}_{2} \mathrm{D}_{4} \mathrm{O}$, is revealed in time-of-flight distributions from the photodissociation of $\mathrm{CD}_{3} \mathrm{CD}_{2} \mathrm{O}$. The product branching ratios and fragment translational energy distributions for all of the observed mass channels are nonstatistical. Moreover, the significant yield of $\mathrm{OH}+\mathrm{C}_{2} \mathrm{H}_{4}$ product suggests that the mechanism for this channel involves isomerization on the excited-state surface. Photodissociation at a much lower yield is seen following excitation at $3.91 \mathrm{eV}$, corresponding to a vibronic band of the $\tilde{\mathrm{B}}^{2} \mathrm{~A}^{\prime} \leftarrow \tilde{\mathrm{X}}^{2} \mathrm{~A}^{\prime \prime}$ transition.

\section{Introduction}

The ethoxy radical has received a great deal of attention due to its importance as an intermediate in combustion and the importance of alkoxy radicals in atmospheric hydrocarbon oxidation. ${ }^{1}$ In combustion, it has been implicated as an intermediate in the reaction of triplet oxygen with ethyl radical, ${ }^{2-4}$ dissociating to products as follows:

$$
\begin{aligned}
& \mathrm{CH}_{3} \mathrm{CH}_{2} \mathrm{O} \rightarrow \mathrm{CH}_{3}+\mathrm{CH}_{2} \mathrm{O} \\
& \mathrm{CH}_{3} \mathrm{CH}_{2} \mathrm{O} \rightarrow \mathrm{H}+\mathrm{CH}_{3} \mathrm{CHO}
\end{aligned}
$$

The ethoxy radical can also be formed following the reaction of the hydroxyl radical with ethylene. The initially formed 2-hydroxyethyl radical can rearrange to form ethoxy $y^{5,6}$

$$
\mathrm{CH}_{2} \mathrm{CH}_{2} \mathrm{OH} \rightarrow \mathrm{CH}_{3} \mathrm{CH}_{2} \mathrm{O}
$$

and proceed to form the products shown above. Unimolecular decomposition of the ethoxy radical itself is not important in the atmosphere, because it is not rapid enough to compete with reaction with molecular oxygen. ${ }^{7}$ However, it may serve as a relatively simple model for the dissociation of larger alkoxy radicals whose unimolecular chemistry is important in the atmosphere. ${ }^{8}$ To learn more about the unimolecular dissociation of this radical, we have carried out a new study of the dissociation dynamics of the ethoxy radical following electronic excitation in the ultraviolet.

Theoretical studies of various combustion reactions on the $\mathrm{C}_{2} \mathrm{H}_{5} \mathrm{O}$ potential energy surface have considered the importance and fate of the ethoxy radical as an intermediate. ${ }^{5-7,9-17}$ As a result of these studies, much of the $\mathrm{C}_{2} \mathrm{H}_{5} \mathrm{O}$ ground-state potential energy surface relevant to unimolecular reactions of ethoxy is fairly well understood. Stationary points relevant to this study, with energies taken from refs 6 and 10, are shown in Figure 1.

* To whom correspondence should be addressed. Electronic mail: dneumark@berkeley.edu.
The lowest activation barriers are for the decomposition reactions to form $\mathrm{CH}_{3}+\mathrm{CH}_{2} \mathrm{O}$ and $\mathrm{H}+\mathrm{CH}_{3} \mathrm{CHO}$, followed by the barriers for isomerization to form $\mathrm{CH}_{2} \mathrm{CH}_{2} \mathrm{OH}$ and $\mathrm{CH}_{3}-$ $\mathrm{CHOH}$. Both of these rearrangements are exothermic. Rate calculations, including recent calculations at temperatures up to $2500 \mathrm{~K},{ }^{16}$ indicate that the rates for both rearrangements are much lower than those for either $\mathrm{CH}_{3}$ or $\mathrm{H}$ atom loss. ${ }^{2,18}$

The reaction of $\mathrm{O}\left({ }^{3} \mathrm{P}\right)$ with ethyl radical, which can lead to the formation of the ethoxy radical with a great deal of excess energy, has been the subject of several experimental studies. $^{2-4,18,19}$ The fragmentation of chemically activated ethoxy radical formed in the reactions of ethyl radical with $\mathrm{O}, \mathrm{O}_{3}$, and $\mathrm{NO}_{3}$ was compared, ${ }^{2}$ and it was found that both $\mathrm{CH}_{3}+\mathrm{CH}_{2} \mathrm{O}$ and $\mathrm{H}+\mathrm{CH}_{3} \mathrm{CHO}$ were formed in all cases. The internal energy of the ethoxy radical formed in these reactions was peaked at roughly $4.0,2.5$, and $1.5 \mathrm{eV}$, respectively. $\mathrm{CH}_{3}+\mathrm{CH}_{2} \mathrm{O}$ formation was favored when $\mathrm{O}_{3}$ and $\mathrm{NO}_{3}$ were used, and the resulting internal energy of the ethoxy radical was lower; when $\mathrm{O}$ was used, the $\mathrm{H}+\mathrm{CH}_{3} \mathrm{CHO}$ channel was favored. $\mathrm{OH}+$ $\mathrm{C}_{2} \mathrm{H}_{4}$ was also seen in this study when ethyl radical reacted with $\mathrm{O}$ and $\mathrm{O}_{3}$, but RRKM calculations implied that this channel was due to direct abstraction of a $\mathrm{H}$ atom from the ethyl radical and did not involve ethoxy as an intermediate. A study of the $\mathrm{OH}$ vibrational energy distribution in $\mathrm{OH}$ generated in the reaction of $\mathrm{O}\left({ }^{3} \mathrm{P}\right)$ and ethyl radical supported the conclusion that these products were formed by direct abstraction. ${ }^{19}$

Spectroscopic studies have yielded information relevant to the ground and excited states of ethoxy. Foster et al. ${ }^{20}$ on the basis of the rotational structure of the laser excitation spectrum, found the symmetry of the ground electronic state to be ${ }^{2} \mathrm{~A}^{\prime \prime}$. Ramond et al., ${ }^{21}$ using anion photoelectron spectroscopy, found the electron affinity for ethoxy to be $1.712 \mathrm{eV}$. The same study also found the splitting between the $\tilde{\mathrm{X}}^{2} \mathrm{~A}^{\prime \prime}$ state and the lowlying $\tilde{\mathrm{A}}^{2} \mathrm{~A}^{\prime}$ state to be $44 \mathrm{meV}$. Laser-induced fluorescence of the $\tilde{\mathrm{B}}^{2} \mathrm{~A}^{\prime} \leftarrow \tilde{\mathrm{X}}^{2} \mathrm{~A}^{\prime \prime}$ transition of ethoxy, for which the origin transition is at $3.618 \mathrm{eV}$, has been the subject of several studies. ${ }^{20,22-24}$ Gopalakrishnan et al. ${ }^{24}$ found that the quantum 


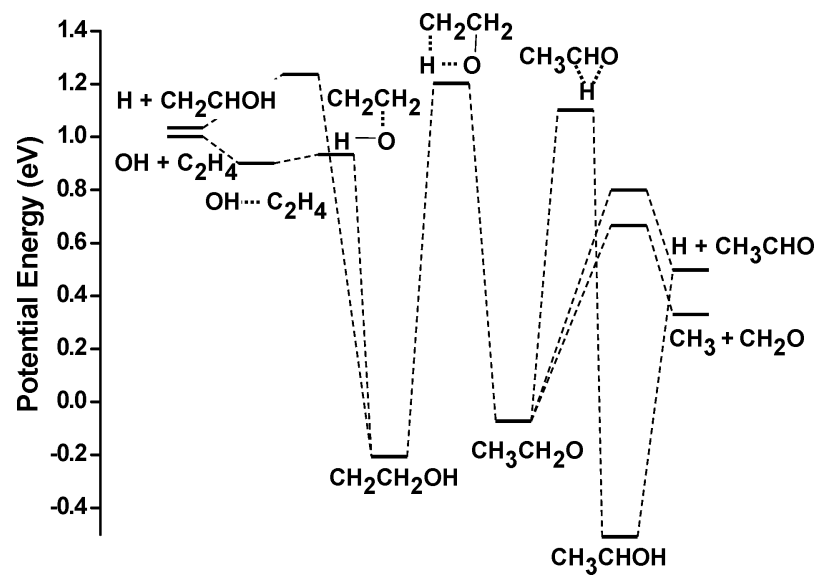

Figure 1. Relevant stationary points on the $\mathrm{C}_{2} \mathrm{H}_{5} \mathrm{O}$ ground-state potential energy surface. Energies are from refs 6 and 10.

yield for fluorescence following this transition drops drastically as the quanta of energy in the $\mathrm{C}-\mathrm{O}$ stretching vibration are increased from 0 to 5 , an effect which they attributed to faster internal conversion to the ground electronic state. Excitation to any of these vibrational levels of the $\tilde{\mathrm{B}}^{2} \mathrm{~A}^{\prime}$ state would provide enough energy to make several dissociation pathways available.

The dynamics of ethoxy radical photodissociation were studied previously by Choi et al..$^{25}$ at excitation energies between 4.77 and $5.96 \mathrm{eV}$ using the technique of fast radical beam photodissociation coupled to coincidence photofragment detection. Many product channels, including all those in Figure 1, are thermodynamically accessible at these energies ${ }^{21,26-31}$

$$
\begin{array}{rlrl}
\mathrm{C}_{2} \mathrm{H}_{5} \mathrm{O}\left(\tilde{\mathrm{X}}^{2} \mathrm{~A}^{\prime \prime}\right) & +h v & \\
& \rightarrow \mathrm{CH}_{3} \mathrm{CO}+\mathrm{H}_{2} & \Delta_{\mathrm{rxn}} H_{298}=0.02 \mathrm{eV} \\
& \rightarrow \mathrm{CH}_{2} \mathrm{CHO}+\mathrm{H}_{2} & \Delta_{\mathrm{rxn}} H_{298}=0.25 \\
& \rightarrow \mathrm{CH}_{2} \mathrm{O}+\mathrm{CH}_{3} & \Delta_{\mathrm{rxn}} H_{298}=0.43 \\
& \rightarrow \mathrm{CH}_{3} \mathrm{CHO}+\mathrm{H} & \Delta_{\mathrm{rxn}} H_{298}=0.67 \\
& \rightarrow \mathrm{C}_{2} \mathrm{H}_{3}+\mathrm{H}_{2} \mathrm{O} & \Delta_{\mathrm{rxn}} H_{298}=0.73 \\
& \rightarrow \mathrm{C}_{2} \mathrm{H}_{4}+\mathrm{O} & \Delta_{\mathrm{rxn}} H_{298}=1.07 \\
\rightarrow \mathrm{CH}_{2} \mathrm{CHOH}+\mathrm{H} & \Delta_{\mathrm{rxn}} H_{298}=1.09 \\
& \rightarrow \mathrm{C}_{2} \mathrm{H}_{5}+\mathrm{O} & \Delta_{\mathrm{rxn}} H_{298}=3.93
\end{array}
$$

Several of the above channels $(3,5,6$, and 8$)$ have very similar fragment mass ratios, the basis upon which products are assigned in this experiment, and the mass resolution was insufficient for an unambiguous determination of the products. On the basis of the shifts in fragment masses between $\mathrm{CH}_{3} \mathrm{CH}_{2} \mathrm{O}$ and $\mathrm{CD}_{3} \mathrm{CD}_{2} \mathrm{O}$, the fragments were identified as $\mathrm{H}_{2} \mathrm{O}$ and vinyl radical (channel 5). However, this assignment was suspect, since formation of these products would require excessive rearrangement (two hydrogen shifts). Moreover, the highest barrier on the groundstate surface was calculated in that study to be $3.23 \mathrm{eV}$, considerably higher than the barriers for other ground-state processes. Therefore, this channel was assigned to excited-state dissociation. No evidence for dissociation from the $\tilde{\mathrm{B}}^{2} \mathrm{~A}^{\prime} \leftarrow$ $\tilde{\mathrm{X}}^{2} \mathrm{~A}^{\prime \prime}$ transition was seen in this work.

These issues led us to reinvestigate the photodissociation dynamics of ethoxy using a new coincidence imaging detector, ${ }^{32}$ which allows us to obtain improved fragment mass resolution and better sensitivity to fragments with low kinetic energy. In addition to the results from coincidence detection, we present

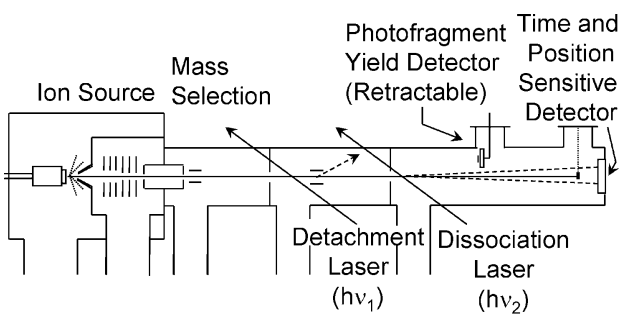

Figure 2. Fast beam photofragment translational spectrometer.

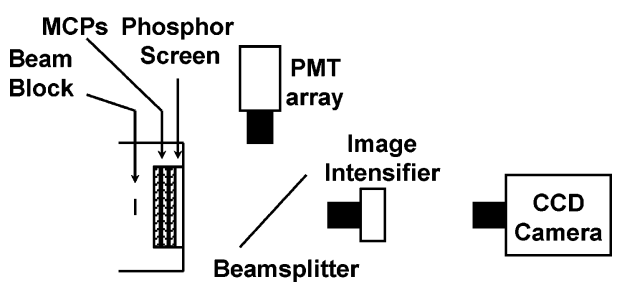

Figure 3. Time and position sensitive detection setup for coincidence imaging.

photofragment time-of-flight measurements that enable the detection of channels in which a light fragment $\left(\mathrm{H}\right.$ or $\left.\mathrm{H}_{2}\right)$ is ejected. The results of our coincidence measurements show that excitation between 5.17 and $5.96 \mathrm{eV}$ leads to significant production of channels 3 and 6, with no evidence for 5. Noncoincidence measurements at $5.17 \mathrm{eV}$ show that the yield of channel 4 is also significant. The upper state in this transition is assigned to the $\tilde{\mathrm{C}}^{2} \mathrm{~A}^{\prime \prime}$ state on the basis of electronic structure calculations on excited states of the ethoxy radical. Finally, we consider the overall dissociation dynamics, in particular, whether these dynamics reflect excited-state or ground-state dissociation. Photodissociation in much lower yield is seen from excitation of the $\tilde{\mathrm{B}}^{2} \mathrm{~A}^{\prime} \leftarrow \tilde{\mathrm{X}}^{2} \mathrm{~A}^{\prime \prime}$ transition.

\section{Experimental Section}

The fast beam photofragment translational spectrometer used in these experiments (Figure 2), including the new photofragment coincidence imaging detector (Figure 3 ) implemented since the previous study of the ethoxy radical, have been described in detail previously. ${ }^{32,33}$ Briefly, a packet of the anion corresponding to the radical of interest, in this case, the ethoxide ion, is mass-selected by time-of-flight, and electrons are photodetached from it by a pulsed dye laser to form the ethoxy radical. The ethoxy radical packet is then intercepted by a second pulsed dye laser to form the photofragments which are detected for each dissociation event, normally in coincidence. The overall experimental scheme can be summarized as

$$
\mathrm{CH}_{3} \mathrm{CH}_{2} \mathrm{O}^{-} \stackrel{h v_{1}}{\longrightarrow} \mathrm{CH}_{3} \mathrm{CH}_{2} \mathrm{O} \stackrel{h v_{2}}{\longrightarrow} \text { fragments }
$$

The ethoxide ion was generated in our pulsed discharge source, ${ }^{34}$ using ethanol as a precursor. A backing gas mixture composed of $20 \% \mathrm{~N}_{2} \mathrm{O}$ and $80 \%$ Ar was bubbled through ethanol at $0{ }^{\circ} \mathrm{C}$ to form the precursor/gas mixture, which flowed directly into the body of the valve at a stagnation pressure of approximately 3 atm. To generate $\mathrm{CD}_{3} \mathrm{CD}_{2} \mathrm{O}$ and $\mathrm{CH}_{3} \mathrm{CD}_{2} \mathrm{O}$, ethanol- $d_{6}$ (D $99 \%$ ) and ethanol-1,1- $d_{2}$ (D 98\%), respectively, were used in place of ethanol. Both were obtained from Cambridge Isotope Laboratories and used without further purification.

The precursor/gas mixture undergoes a supersonic expansion through a pulsed piezoelectric valve with a pair of pulsed discharge plates fitted to the faceplate and a $1 \mathrm{keV}$ electron beam passing just in front of the discharge plates. The mixture 
of species formed in the discharge source is collimated by a skimmer, and the negative ions are accelerated to a final beam energy of 5 or $9 \mathrm{keV}$ and focused by an einzel lens. Ions then pass through a collinear time-of-flight mass spectrometer, where they are separated by mass. A XeCl excimer-pumped dye laser is fired as the ions of the desired mass pass through the laser beam path in order to detach an electron. The undetached ions are then deflected from the beam path. The neutral radicals are intercepted by a second laser pulse from a frequency-doubled, $\mathrm{XeCl}$ excimer-pumped dye laser. The bandwidths of the detachment and dissociation dye lasers (which were used without etalons) are 0.2 and $0.15 \mathrm{~cm}^{-1}$, respectively.

The detachment laser is tuned sufficiently above the detachment threshold to obtain an adequate detachment cross-section, while minimizing the internal energy of the radical. Detachment photon energies $\left(h v_{\text {det }}\right)$ of $1.797 \mathrm{eV}$ for $\mathrm{CH}_{3} \mathrm{CH}_{2} \mathrm{O}^{-}$and 1.771 $\mathrm{eV}$ for $\mathrm{CD}_{3} \mathrm{CD}_{2} \mathrm{O}^{-}$were used. These energies are above the thresholds for detachment to the low-lying $\tilde{\mathrm{A}}^{2} \mathrm{~A}^{\prime}$ state, which were found by Ramond et al. to be 1.756 and $1.733 \mathrm{eV}$ for $\mathrm{CH}_{3} \mathrm{CH}_{2} \mathrm{O}^{-}$and $\mathrm{CD}_{3} \mathrm{CD}_{2} \mathrm{O}^{-}$, respectively. ${ }^{21}$ Therefore, at the detachment energies listed above, the radical can be formed in both the $\tilde{\mathrm{X}}^{2} \mathrm{~A}^{\prime \prime}$ and $\tilde{\mathrm{A}}^{2} \mathrm{~A}^{\prime}$ electronic states, but only in the ground vibrational state of each. For $\mathrm{CH}_{3} \mathrm{CD}_{2} \mathrm{O}^{-}$, detachment photon energies of 1.771 and $1.728 \mathrm{eV}$ were used, which are above and below the threshold for detachment to the $\tilde{\mathrm{A}}^{2} \mathrm{~A}^{\prime}$ state, respectively, as shown by our electronic structure calculations described in section III. Dissociation photon energies $\left(h v_{\text {diss }}\right)$ ranged from 5.17 to $5.96 \mathrm{eV}$, over which a largely unstructured photofragment yield spectrum and coincidence photofragment distributions were previously acquired. ${ }^{25}$ Photodissociation was also attempted at $3.91284 \mathrm{eV}$, corresponding to the energy of the sharp $v=4 \leftarrow 0$ band of the $\mathrm{C}-\mathrm{O}$ stretching mode in the $\tilde{\mathrm{B}}^{2} \mathrm{~A}^{\prime} \leftarrow \tilde{\mathrm{X}}^{2} \mathrm{~A}^{\prime \prime}$ transition. ${ }^{24}$

Photofragments from the second laser pulse continue another $2 \mathrm{~m}$ along the beam path before hitting the time and position sensitive detector. This detector consists of a Z-stack of three microchannel plates (MCPs) coupled to a phosphor screen and is $75 \mathrm{~mm}$ in diameter. Undissociated neutrals are prevented from hitting the detector by a $5 \mathrm{~mm} \times 8 \mathrm{~mm}$ beam block positioned in front of the detector in the beam path. The image from the phosphor screen is split by a dichroic beam splitter, and transmitted and reflected images are focused onto an image intensifier in front of a charge-coupled device (CCD) camera and a $4 \times 4$ photomultiplier tube (PMT) array, respectively. For each dissociation event, the positions of the fragments are determined from the CCD camera image, and the arrival times from the PMTs.

In the standard coincidence mode of operation, the fragments from each dissociation event are detected in coincidence. The positions and arrival times of fragments then give the threedimensional recoil geometry of the fragments for that event, from which $E_{\mathrm{T}}$ (the translational kinetic energy release) and $\theta$ (the angle between the dissociation laser polarization, which is parallel to the neutral beam for all of the data reported here, and the recoil vector) are calculated. By analysis of many dissociation events, fragment mass distributions, $P\left(E_{\mathrm{T}}\right)$ distributions, and $\beta\left(E_{\mathrm{T}}\right)$ (anisotropy parameters) are determined.

The relatively poor mass resolution for the coincidence data in this experiment is due to the finite size of the parent beam and increases approximately linearly with the ratio of the distance between the points of impact of the fragments on the detector to the width of the parent beam. Therefore, the mass resolution in this study is improved in comparison to that in our previous study of the ethoxy radical because of the greater diameter of this detector ( $75 \mathrm{~mm}$ vs $40 \mathrm{~mm}$ ). Under identical conditions, the greater detector diameter would yield a small improvement in the resolution in the fragment mass distributions. In this study, the flight time of the fragments was increased by using a longer flight length and a lower beam energy, thereby increasing the separation of the fragments on the detector for given values of $E_{\mathrm{T}}$ and $\theta$, which in turn further improves the resolution in the fragment mass distributions. The uncertainty in mass, as characterized by the full width at half-maximum of a single mass peak in the fragment mass distributions, appears to be improved from $\Delta m \approx 2.7$ amu to $2.0 \mathrm{amu}$.

Because of the beam block and finite size of the detector, it is not possible to detect both fragments from all events. Further, events in which one or both fragments hit in the inner $8.6 \mathrm{~mm}$ of the detector had to be rejected in this study in order to distinguish between different mass channels, and events in which one or more fragments appear to hit in the outer $1 \mathrm{~mm}$ of the detector must be rejected because their positions cannot generally be calculated correctly. The probability of detecting both fragments from an event on the remaining surface of the detector depends on both $E_{\mathrm{T}}$ and $\theta$ and is corrected for using a detector acceptance function similar to that described by Continetti et al. ${ }^{33}$

Coincidence detection of the two fragments, as described above, is possible only when the ratio of the fragment masses (heavy mass/light mass) is less than about 10:1. Otherwise, whenever the heavier fragment recoils far enough in the plane of the detector to clear the beam block, the lighter fragment will fly clear of the detector. To determine whether photodissociation products with a greater mass ratio, i.e., the products of reactions $1,2,4$, or 7 , were produced, further experiments were performed in which the positions and times of arrival of all fragments were saved and analyzed regardless of whether a second fragment from the same dissociation event was detected. This differs from the noncoincidence experiments performed previously in this laboratory ${ }^{35,36}$ in that the fragment times of arrival are determined from the signal from a PMT array trained on the phosphor screen (see Figure 3), rather than the signal directly from an MCP. Results and analysis of data collected in this mode are described in section IIIC.

\section{Results}

A. Coincidence Detection: Fragment Mass Distributions. Fragment mass distributions for the photodissociation of $\mathrm{CH}_{3} \mathrm{CH}_{2} \mathrm{O}, \mathrm{CD}_{3} \mathrm{CD}_{2} \mathrm{O}$, and $\mathrm{CH}_{3} \mathrm{CD}_{2} \mathrm{O}$ at $5.17 \mathrm{eV}$ are shown in Figure 4. $\mathrm{CH}_{3} \mathrm{CH}_{2} \mathrm{O}$ and $\mathrm{CD}_{3} \mathrm{CD}_{2} \mathrm{O}$ fragment mass distributions are compared in Figure $4 \mathrm{a}$, while Figure $4 \mathrm{~b}$ compares $\mathrm{CH}_{3} \mathrm{CD}_{2} \mathrm{O}$ distributions with photodetachment energies below and above the threshold for detachment to the $\tilde{\mathrm{A}}^{2} \mathrm{~A}^{\prime}$ state. The detachment energies in Figure $4 \mathrm{a}$ were above the threshold for detachment to the $\tilde{\mathrm{A}}^{2} \mathrm{~A}^{\prime}$ state.

The fragment mass distribution for $\mathrm{CH}_{3} \mathrm{CH}_{2} \mathrm{O}$ shows a pair of partially resolved doublets, suggesting fragment pairs with masses 15 and 30 amu and 17 and 28 amu, which would correspond to $\mathrm{CH}_{3}+\mathrm{CH}_{2} \mathrm{O}$ and $\mathrm{OH}+\mathrm{C}_{2} \mathrm{H}_{4}$, respectively. Fragment mass distributions for this isotopomer at 5.64 and 5.96 $\mathrm{eV}$ (not shown) are essentially identical to that at $5.17 \mathrm{eV}$. The fragment mass distribution for $\mathrm{CD}_{3} \mathrm{CD}_{2} \mathrm{O}$ shows two peaks, narrower than those for $\mathrm{CH}_{3} \mathrm{CH}_{2} \mathrm{O}$, centered at 18 and $32 \mathrm{amu}$. This result confirms the above assignments and eliminates the possibility of a contribution from masses 16 and 29 in the $\mathrm{CH}_{3} \mathrm{CH}_{2} \mathrm{O}$ fragment mass distribution, since $\mathrm{CD}_{3}+\mathrm{CD}_{2} \mathrm{O}$ and $\mathrm{OD}+\mathrm{C}_{2} \mathrm{D}_{4}$ are the only possible fragments of $\mathrm{CD}_{3} \mathrm{CD}_{2} \mathrm{O}$ that would have masses of 18 and $32 . \mathrm{C}_{2} \mathrm{H}_{3}+\mathrm{H}_{2} \mathrm{O}$, the products 


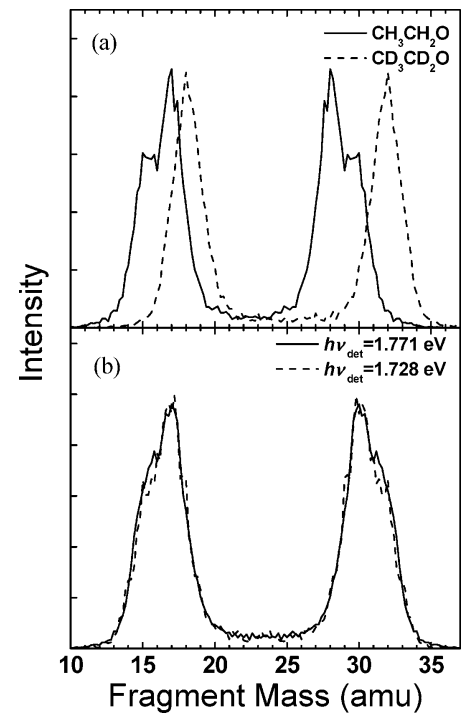

Figure 4. Fragment mass distributions for photodissociation of the various isotopomers of ethoxy used in this study at $5.17 \mathrm{eV}$. In (a), the solid line is the plot for $\mathrm{CH}_{3} \mathrm{CH}_{2} \mathrm{O}$ and the dashed line is for $\mathrm{CD}_{3} \mathrm{CD}_{2} \mathrm{O}$. (b) shows the plots for $\mathrm{CH}_{3} \mathrm{CD}_{2} \mathrm{O}$; the solid line is for a detachment energy of $1.771 \mathrm{eV}$, and the dashed line is for a detachment energy of $1.728 \mathrm{eV}$.

inferred in the previous study of ethoxy radical photodissociation by Choi et al., ${ }^{25}$ would lead to peaks at 18 and 27 amu for $\mathrm{CH}_{3} \mathrm{CH}_{2} \mathrm{O}$ and 20 and $30 \mathrm{amu}$ for $\mathrm{CD}_{3} \mathrm{CD}_{2} \mathrm{O}$. The poorer mass resolution in that study, in addition to making the absolute determination of the peak positions more difficult, obscured the narrowing of the peaks upon deuteration and gave the appearance that only two peaks, which shifted by 2 and 3 amu upon deuteration, hence resulting from $\mathrm{C}_{2} \mathrm{H}_{3}+\mathrm{H}_{2} \mathrm{O}\left(\mathrm{C}_{2} \mathrm{D}_{3}+\mathrm{D}_{2} \mathrm{O}\right)$, were present. With the improved mass resolution of this study, it is apparent that peaks corresponding to $\mathrm{C}_{2} \mathrm{H}_{3}+\mathrm{H}_{2} \mathrm{O}$ are not present in the fragment mass distributions. $\mathrm{CH}_{3} \mathrm{CD}_{2} \mathrm{O}$ forms fragment pairs with masses 15 and 32 amu and 17 and $30 \mathrm{amu}$, indicating the formation of $\mathrm{CH}_{3}+\mathrm{CD}_{2} \mathrm{O}$ and $\mathrm{OH}+\mathrm{C}_{2} \mathrm{D}_{2} \mathrm{H}_{2}$, for both detachment energies used. No evidence for OD production is seen, showing that the hydrogen atom in the hydroxyl radical originates on the methyl carbon.

B. Coincidence Detection: Translational Energy and Angular Distributions. Fragment translational energy distributions $\left(P\left(E_{\mathrm{T}}\right)\right)$ and anisotropy parameters $\left(\beta\left(E_{\mathrm{T}}\right)\right)$ are determined by fitting the intensity as a function of translational energy and recoil angle, $P\left(E_{\mathrm{T}}, \theta\right)$ (which has been corrected for the detector acceptance function, as described in section II), to the equation

$$
P\left(E_{\mathrm{T}}, \theta\right)=P\left(E_{\mathrm{T}}\right)\left[1+\beta\left(E_{\mathrm{T}}\right) P_{2}(\cos \theta)\right]
$$

where $\theta$ is the angle between the electric field vector of the photodissociation laser and the recoil vector between the photofragments. The anisotropy parameter $\beta\left(E_{\mathrm{T}}\right)$ ranges from -1 for a $\sin ^{2} \theta$ distribution to 2 for a $\cos ^{2} \theta$ distribution. At very low translational energies, and at those above about $1-1.5$ $\mathrm{eV}$, depending on the amount of data, it is not possible to determine $\beta\left(E_{\mathrm{T}}\right)$ accurately because of the scarcity of events and the small range of $\theta$ for which the detector acceptance function is nonzero. For these energies, $\beta\left(E_{\mathrm{T}}\right)$ is fixed at the value determined for it at the nearest energy possible, and the best fit to $P\left(E_{\mathrm{T}}, \theta\right)$ is found by varying only $P\left(E_{\mathrm{T}}\right)$.

Figure 5 shows $P\left(E_{\mathrm{T}}\right)$ (open circles) and $\beta\left(E_{\mathrm{T}}\right)$ for the $\mathrm{CH}_{3}$ $+\mathrm{CH}_{2} \mathrm{O}$ and $\mathrm{OH}+\mathrm{C}_{2} \mathrm{H}_{4}$ channels for $\mathrm{CH}_{3} \mathrm{CH}_{2} \mathrm{O}$ at photodissociation energies of 5.17, 5.64, and $5.96 \mathrm{eV}$. Figure 6 shows results for $\mathrm{CH}_{3} \mathrm{CD}_{2} \mathrm{O}$ at $5.17 \mathrm{eV}$, but at photodetachment

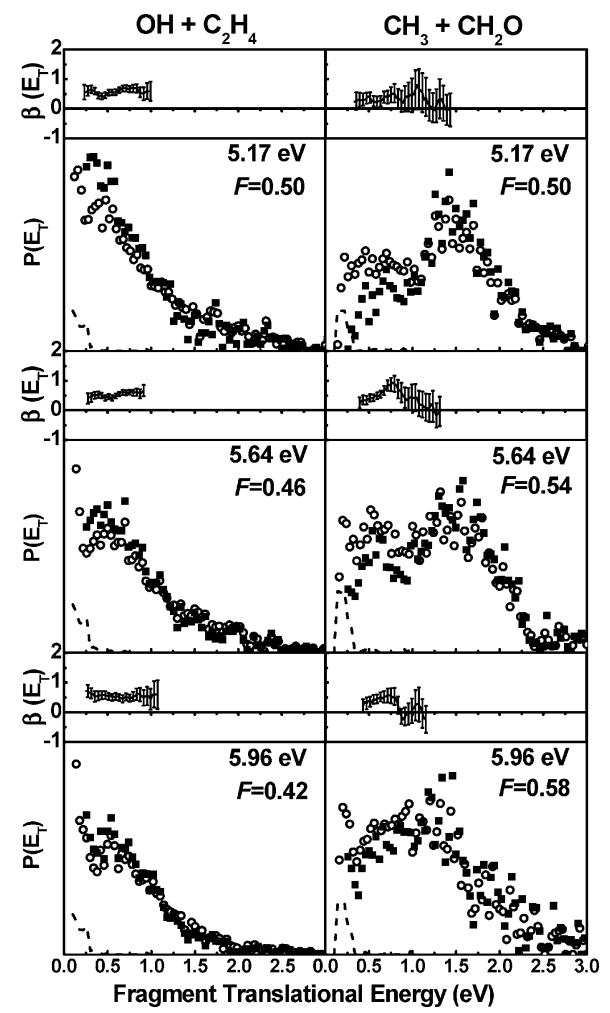

Figure 5. $P\left(E_{\mathrm{T}}\right)$ distributions (open circles), $\beta\left(E_{\mathrm{T}}\right)$, corrected $P\left(E_{\mathrm{T}}\right)$ distributions (squares, see text), and background dissociation (dashed lines) for $\mathrm{C}_{2} \mathrm{H}_{5} \mathrm{O}$ at the dissociation photon energies indicated. $F$ indicates the branching fraction, considering only the $\mathrm{CH}_{3}+\mathrm{CH}_{2} \mathrm{O}$ and $\mathrm{OH}+\mathrm{C}_{2} \mathrm{H}_{4}$ product channels.

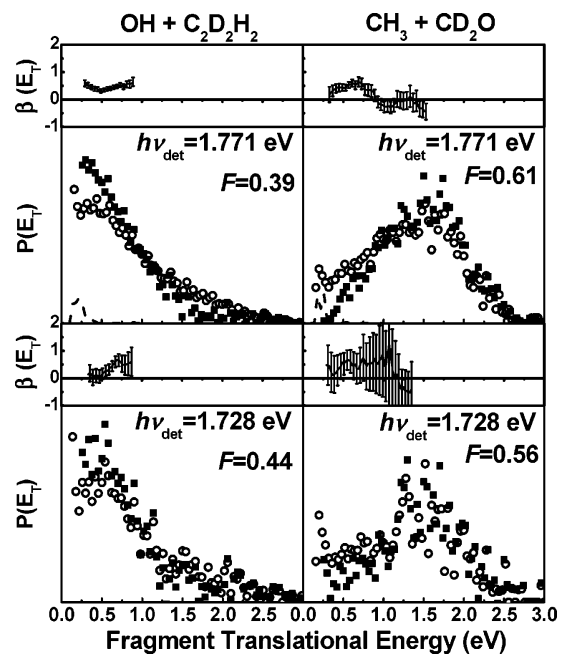

Figure 6. $P\left(E_{\mathrm{T}}\right)$ distributions (open circles), $\beta\left(E_{\mathrm{T}}\right)$, corrected $P\left(E_{\mathrm{T}}\right)$ distributions (squares), and background dissociation (lines) for $\mathrm{CH}_{3} \mathrm{CD}_{2} \mathrm{O}$ at a dissociation photon energy of $5.17 \mathrm{eV}$. In the top two plots, the detachment photon energy is $1.771 \mathrm{eV}$; in the bottom two plots, it is $1.728 \mathrm{eV} . F$ indicates the branching fraction, considering only the $\mathrm{CH}_{3}+\mathrm{CD}_{2} \mathrm{O}$ and $\mathrm{OH}+\mathrm{C}_{2} \mathrm{D}_{2} \mathrm{H}_{2}$ product channels.

energies above $\left(h v_{\text {det }}=1.771 \mathrm{eV}\right)$ and below $\left(h v_{\text {det }}=1.728\right.$ $\mathrm{eV}$ ) the threshold for the $\tilde{\mathrm{A}}^{2} \mathrm{~A}^{\prime}$ state. The signal-to-noise ratio is much worse at $h v_{\mathrm{det}}=1.728 \mathrm{eV}$, consistent with the (about 5 times) smaller photodetachment cross-section at the lower photodetachment energy; otherwise, there is little difference between the results for the two detachment energies.

In Figures 5 and 6, the $P\left(E_{\mathrm{T}}\right)$ distributions for the $\mathrm{OH}+\mathrm{C}_{2} \mathrm{H}_{4}$ $\left(\mathrm{OH}+\mathrm{C}_{2} \mathrm{D}_{2} \mathrm{H}_{2}\right)$ channel at $5.17 \mathrm{eV}$ peak near $E_{\mathrm{T}}=0$ and fall nearly monotonically with increasing $E_{\mathrm{T}}$. At the two higher energies (Figure 5), the distributions move out to higher $E_{\mathrm{T}}$, 
extending to around $0.5 \mathrm{eV}$ before dropping off in intensity. Another small feature, peaked very near $0 \mathrm{eV}$, is present in all of these $P\left(E_{\mathrm{T}}\right)$ distributions, but appears to be an artifact, possibly from collision-induced dissociation, since it is observed in the absence of the photodissociation laser. The apparent $P\left(E_{\mathrm{T}}\right)$ for this channel calculated from the background dissociation is shown as a dashed line. Once this effect is taken into account, all of the $P\left(E_{\mathrm{T}}\right)$ distributions for this channel peak between 0.4 and $0.6 \mathrm{eV}$.

The $P\left(E_{\mathrm{T}}\right)$ distributions for the $\mathrm{CH}_{3}+\mathrm{CH}_{2} \mathrm{O}$ channel are somewhat more complicated. All of the $P\left(E_{\mathrm{T}}\right)$ distributions for this channel show significant intensity from about $0.15 \mathrm{eV}$ to $2.5 \mathrm{eV}$. However, the resolution between the $\mathrm{CH}_{3}+\mathrm{CH}_{2} \mathrm{O}$ mass channel and the $\mathrm{OH}+\mathrm{C}_{2} \mathrm{H}_{4}$ channel is imperfect, particularly at the lowest fragment translational energies. Thus, although all of the $P\left(E_{\mathrm{T}}\right)$ distributions for this channel show high intensity around $0.5 \mathrm{eV}$, it is likely that some of this intensity is due to inadequate resolution of the mass channels, since this is where the $P\left(E_{\mathrm{T}}\right)$ for the $\mathrm{OH}+\mathrm{C}_{2} \mathrm{H}_{4}$ channel is highest. The apparent $P\left(E_{\mathrm{T}}\right)$ for the background dissociation assigned to the $\mathrm{CH}_{3}+$ $\mathrm{CH}_{2} \mathrm{O}$ channel, scaled by the same factor as that used for the $\mathrm{OH}+\mathrm{C}_{2} \mathrm{H}_{4}$ channel, is shown as a dashed line, showing that some of the intensity at very low translational energy must be an artifact due to background dissociation. Once these artifacts are taken into account, it follows that much of the signal at higher translational energies, where the $P\left(E_{\mathrm{T}}\right)$ for the $\mathrm{OH}+$ $\mathrm{C}_{2} \mathrm{H}_{4}$ channel drops off, must be from true photodissociation to $\mathrm{CH}_{3}+\mathrm{CH}_{2} \mathrm{O}$. The $P\left(E_{\mathrm{T}}\right)$ for $\mathrm{CH}_{3}+\mathrm{CD}_{2} \mathrm{O}$ with $h v_{\text {det }}=$ $1.771 \mathrm{eV}$ in Figure 6 appears to be dominated by a single, broad feature centered near $1.5 \mathrm{eV}$. These data were acquired under more optimal conditions than any of the datasets for $\mathrm{CH}_{3} \mathrm{CH}_{2} \mathrm{O}$ and reflect about twice as many dissociation events and a shorter data acquisition time.

$\beta\left(E_{\mathrm{T}}\right)$ is positive for the $\mathrm{OH}+\mathrm{C}_{2} \mathrm{H}_{4}$ channel over the translational energy range where it can be reliably calculated. The $\beta\left(E_{\mathrm{T}}\right)$ plots for the $\mathrm{CH}_{3}+\mathrm{CH}_{2} \mathrm{O}$ channel all show values similar to those for the $\mathrm{OH}+\mathrm{C}_{2} \mathrm{H}_{4}$ channel between 0.5 and $0.7 \mathrm{eV}$, where the intensity is likely to be mostly due to incorrectly assigned events from that channel, and drop to about 0 near $1 \mathrm{eV}$, where the higher-energy feature in the $P\left(E_{\mathrm{T}}\right)$ begins to dominate. While not much can be said about how $\beta\left(E_{\mathrm{T}}\right)$ varies with translational energy, $\beta\left(E_{\mathrm{T}}\right)$ values for this channel appear to be 0 or slightly negative at all dissociation photon energies.

It is possible to estimate the amount of signal from each mass channel that is misassigned. If the neutral beam cross-section is assumed to be a Gaussian, the probability of calculating a given mass ratio for a dissociation event is nearly a Gaussian distribution centered at the correct mass ratio. The fraction of events from one channel that are assigned to another channel, the calculated mass ratios for which form a Gaussian distribution overlapping the first, is equal to the fraction of the area under the curve representing the distribution of calculated mass ratios for the first channel that is closer to the true mass ratio for the second channel. The corrected $P\left(E_{\mathrm{T}}\right)$ distributions using this estimate, with the overlap calculated separately for each 0.02 $\mathrm{eV}$ energy bin, are shown by the squares in Figures 5 and 6 . The corrected $P\left(E_{\mathrm{T}}\right)$ distributions for $\mathrm{CH}_{3}+\mathrm{CH}_{2} \mathrm{O}$ obtained in this way more closely resemble broad peaks centered between 1 and $1.5 \mathrm{eV}$. Relative yields for the $\mathrm{OH}+\mathrm{C}_{2} \mathrm{H}_{4}(\mathrm{OH}+$ $\left.\mathrm{C}_{2} \mathrm{D}_{2} \mathrm{H}_{2}\right)$ and $\mathrm{CH}_{3}+\mathrm{CH}_{2} \mathrm{O}\left(\mathrm{CH}_{3}+\mathrm{CD}_{2} \mathrm{O}\right)$ product channels, calculated by integrating $P\left(E_{\mathrm{T}}\right)$ over the range shown in the plots, are included in the figures. The uncertainty for these relative yields is roughly \pm 0.15 , and the relative yields for the different energies are all the same within the uncertainty.

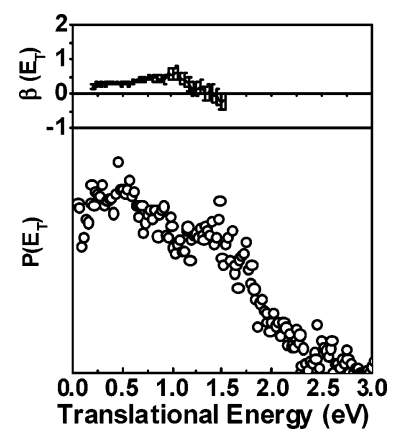

Figure 7. $P\left(E_{\mathrm{T}}\right)$ distribution and $\beta\left(E_{\mathrm{T}}\right)$ for $\mathrm{C}_{2} \mathrm{D}_{5} \mathrm{O}$ at a dissociation photon energy of $5.17 \mathrm{eV}$.

For $\mathrm{CD}_{3} \mathrm{CD}_{2} \mathrm{O}$, the two product channels produce the same pair of masses, so the data from the two channels cannot be resolved at all. The $P\left(E_{\mathrm{T}}\right)$ distribution, shown in Figure 7, appears as would be expected on the basis of the $P\left(E_{\mathrm{T}}\right)$ distributions for $\mathrm{CH}_{3} \mathrm{CH}_{2} \mathrm{O}$ at $5.17 \mathrm{eV} . \beta\left(E_{\mathrm{T}}\right)$ is close to 0.5 for translational energies at which the $\mathrm{OD}+\mathrm{C}_{2} \mathrm{D}_{4}$ channel would be expected to dominate, up to about $1 \mathrm{eV}$, then drops to about 0 at $1.2 \mathrm{eV}$, where signal from $\mathrm{CD}_{3}+\mathrm{CD}_{2} \mathrm{O}$ begins to dominate.

An attempt was also made to study photodissociation of $\mathrm{CH}_{3} \mathrm{CH}_{2} \mathrm{O}$ at $3.91284 \mathrm{eV}$, the energy of the $v=4 \leftarrow 0$ band of the $\mathrm{C}-\mathrm{O}$ stretch ${ }^{24}$ in the $\tilde{\mathrm{B}}^{2} \mathrm{~A}^{\prime} \leftarrow \tilde{\mathrm{X}}^{2} \mathrm{~A}^{\prime \prime}$ transition. While some photodissociation was seen at this energy, the rate of photodissociation was not high enough compared to the rate of background dissociation to obtain meaningful fragment mass or translational energy distributions. We estimate the photofragment yield at $3.91284 \mathrm{eV}$ to be roughly $1 / 10$ that at $5.17 \mathrm{eV}$ on the basis of the relative intensity of peaks in the arrival time distribution due solely to background and those due to a combination of background and photodissociation.

C. Noncoincidence Detection: Time-of-Flight Distributions. The time-of-flight distributions for $\mathrm{CD}_{3} \mathrm{CD}_{2} \mathrm{O}$ dissociation at a dissociation photon energy of $5.17 \mathrm{eV}$ and beam energies of 5 and $9 \mathrm{keV}$, with background subtracted, are shown by the circles in Figure 8. As explained in section II, these experiments were carried out in order to investigate fragment channels with a high mass ratio (i.e., $\mathrm{H}$ or $\mathrm{H}_{2}$ loss), for which coincidence detection is unsuitable. The fully deuterated isotopomer was used in order to increase the chances that the heavy fragment would clear the beam block and that the light fragment would be detected. There is considerably higher background at earlier times in both of these distributions, resulting in higher baseline noise after background subtraction.

Analysis of the time-of-flight distributions is accomplished by simulation using a forward convolution program. ${ }^{36}$ The input for this simulation consists of a $P\left(E_{\mathrm{T}}\right)$ distribution and an energyindependent anisotropy parameter, $\beta$, for each product channel. For the product channels already determined by analysis of the coincidence data, $\mathrm{OD}+\mathrm{C}_{2} \mathrm{D}_{4}$ and $\mathrm{CD}_{3}+\mathrm{CD}_{2} \mathrm{O}$, the $P\left(E_{\mathrm{T}}\right)$ from Figure 7 and $\beta=0.33$ (determined by averaging over $\beta\left(E_{\mathrm{T}}\right)$ in Figure 7$)$ were used. The resulting time-of-fight distributions, signifying the contribution from these channels, are shown by the dotted lines in Figure 8. Comparison of this contribution with the experimental data shows that a product channel with a higher mass ratio is also present.

Generating the fit for this additional product channel requires knowledge of the fragment masses. Channel $4, \mathrm{D}+\mathrm{CD}_{3} \mathrm{CDO}$, would be expected to be much more favorable than $\mathrm{D}_{2}$ loss (channels 1 and 2), since these would require high-energy 3and 4-center transition states, and somewhat more favorable than channel 7 (D $\left.+\mathrm{CD}_{2} \mathrm{CDOD}\right)$, which would require rearrangement through a 4-center transition state. Channels involving the 


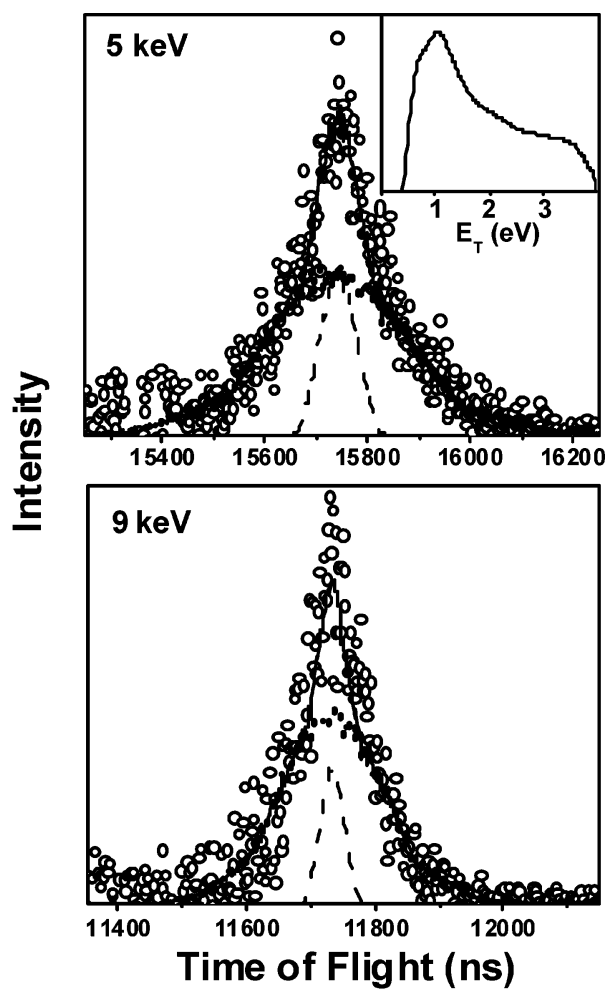

Figure 8. Time-of-flight distributions for $\mathrm{C}_{2} \mathrm{D}_{5} \mathrm{O}$ at beam acceleration energies of 5 and $9 \mathrm{keV}$ and a dissociation photon energy of $5.17 \mathrm{eV}$. Circles are the experimental data, solid lines are a fit to the data, dashed lines are the mass 2 and 48 amu component of the fit, and dotted lines are the mass 18 and 32 amu component of the fit. The $P\left(E_{\mathrm{T}}\right)$ distribution in the inset was used in generating the mass 2 and 48 amu component of the fit.

loss of $2 \mathrm{D}$ atoms would leave almost no available excess energy, ruling them out as a source of all but the lowest-velocity fragments observed. Since, further, $\mathrm{H}+\mathrm{CH}_{3} \mathrm{CHO}$ is known to be a major product channel from the unimolecular decomposition of ethoxy, we have used masses 2 and 48 amu $\left(D+C_{2} D_{4} \mathrm{O}\right)$ as the only mass channel of high mass ratio in this analysis. The time-of-flight distribution for this channel, shown by the dashed lines in Figure 8, was simulated using the $P\left(E_{\mathrm{T}}\right)$ distribution shown in the inset and $\beta=0$. The $\mathrm{D}$-atom signal is not visible on the scale of these plots, because it is spread out over many more time bins than the heavy-fragment signal; its maximum intensity is about 100 times less than that for the heavy fragment, even assuming its detection efficiency to be the same. In fact, the detection efficiency of the D atom is expected to be much lower because of its lower translational energy along the beam axis in the laboratory frame.

The relative yields for the mass 2 and 48 amu and mass 18 and 32 amu channels, which are proportional to the scaling factors used to fit the data, are 0.36 and 0.64 , respectively. It is reasonable to assume that the relative yields of $\mathrm{CD}_{3}+\mathrm{CD}_{2} \mathrm{O}$ and $\mathrm{OD}+\mathrm{C}_{2} \mathrm{D}_{4}$ are the same as those for $\mathrm{CH}_{3}+\mathrm{CH}_{2} \mathrm{O}$ and $\mathrm{OH}+\mathrm{C}_{2} \mathrm{H}_{4}$ from $\mathrm{CH}_{3} \mathrm{CH}_{2} \mathrm{O}$ at this energy within error. The branching fractions calculated using this assumption are 0.36 for $\mathrm{D}+\mathrm{C}_{2} \mathrm{D}_{4} \mathrm{O}, 0.32$ for $\mathrm{CD}_{3}+\mathrm{CD}_{2} \mathrm{O}$, and 0.32 for $\mathrm{OD}+$ $\mathrm{C}_{2} \mathrm{D}_{4}$.

D. Electronic Structure Calculations. Electronic structure calculations on the ethoxy radical were carried out for three purposes. The first is to identify the excited electronic state of ethoxy accessed at dissociation photon energies between 5.17 and $5.96 \mathrm{eV}$. The second is to determine the threshold for formation of $\mathrm{CH}_{3} \mathrm{CD}_{2} \mathrm{O}$ in the $\tilde{\mathrm{A}}^{2} \mathrm{~A}^{\prime}$ electronic state by detachment of an electron from $\mathrm{CH}_{3} \mathrm{CD}_{2} \mathrm{O}^{-}$by calculating the zero-

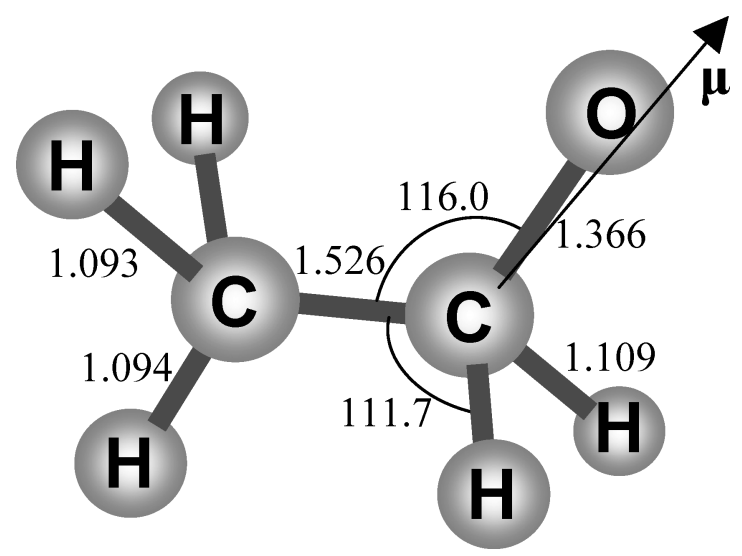

Figure 9. Ground-state geometry of the ethoxy radical obtained from B3LYP/6-311++ $\mathrm{G}^{* *}$. Bond lengths are in angstroms, and angles are in degrees. $\mu$ is the transition dipole for the $\tilde{\mathrm{C}}^{2} \mathrm{~A}^{\prime \prime} \leftarrow \tilde{\mathrm{X}}^{2} \mathrm{~A}^{\prime \prime}$ transition, obtained from TD-B3LYP/6-311++ $\mathrm{G}^{* *}$, and lies in the $\mathrm{C}-\mathrm{C}-\mathrm{O}$ plane. The figure is not drawn to scale.

TABLE 1: Vertical Excitation Energies and Oscillator Strengths Predicted by TD-B3LYP/6-311++G**a

\begin{tabular}{clcc}
\hline method & \multicolumn{1}{c}{ transition } & $\begin{array}{c}\text { excitation } \\
\text { energy }(\mathrm{eV})\end{array}$ & $\begin{array}{c}\text { oscillator } \\
\text { strength }\end{array}$ \\
\hline TD-B3LYP & $1\left(\tilde{\mathrm{A}}\left(\mathrm{A}^{\prime}\right) \leftarrow \tilde{\mathrm{X}}\left(\mathrm{A}^{\prime \prime}\right)\right)$ & 0.332 & 0.0001 \\
& $2\left(\tilde{\mathrm{B}}\left(\mathrm{A}^{\prime}\right) \leftarrow \tilde{\mathrm{X}}\left(\mathrm{A}^{\prime \prime}\right)\right)$ & 4.194 & 0.0010 \\
& $3\left(\tilde{\mathrm{C}}\left(\mathrm{A}^{\prime \prime}\right) \leftarrow \tilde{\mathrm{X}}\left(\mathrm{A}^{\prime \prime}\right)\right)$ & 5.056 & 0.0208 \\
exptl & $4\left(\tilde{\mathrm{D}}\left(\mathrm{A}^{\prime}\right) \leftarrow \tilde{\mathrm{X}}\left(\mathrm{A}^{\prime \prime}\right)\right)$ & 5.678 & 0.0007 \\
& $\tilde{\mathrm{A}}\left(\mathrm{A}^{\prime}\right) \leftarrow \tilde{\mathrm{X}}\left(\mathrm{A}^{\prime \prime}\right)$ & $0.044^{21}$ & \\
& $\tilde{\mathrm{B}}\left(\mathrm{A}^{\prime}\right) \leftarrow \tilde{\mathrm{X}}\left(\mathrm{A}^{\prime \prime}\right)$ & $3.618^{24}$ &
\end{tabular}
batic.

${ }^{a}$ Experimental excitation energies shown for comparison are adia-

point corrections to the energies of the species involved. The third is to determine the parameters required to calculate RRKM rate constants for the observed product channels at the excitation energies used in this study in order to aid in the interpretation of our experimental results. All calculations were carried out using the Gaussian 03 program package. ${ }^{37}$

In the first set of calculations, in which the goal was to learn more about the electronic transition(s) of the ethoxy radical being excited in these experiments, the B3LYP method with the $6-311++\mathrm{G}^{* *}$ basis set was used for geometry optimization of the ground electronic state of ethoxy, and the TD-B3LYP method, with the same basis set, was used for the excited-state calculation. SAC-CI calculations using the same basis set (results not shown) give the same symmetry ordering for the first four states. The calculated energies for the first four transitions show little change with the addition of diffuse functions (the largest difference between the energies calculated with the $6-311 \mathrm{G}^{* *}$ and $6-311++\mathrm{G}^{* *}$ basis sets was $0.24 \mathrm{eV}$ ), indicating that the excitations are free of Rydberg character, which TD-B3LYP calculations do not treat accurately. ${ }^{38}$ These states do not show significant spin contamination.

The ground-state geometry optimized at the B3LYP/ $6-311++\mathrm{G}^{* *}$ level, which was used in the excited-state calculation, is shown in Figure 9. The energies and oscillator strengths for the first four electronic transitions found in our excitedstate calculation are shown in Table 1 , along with experimental values of the energies for the $\tilde{\mathrm{A}}^{2} \mathrm{~A}^{\prime} \leftarrow \tilde{\mathrm{X}}^{2} \mathrm{~A}^{\prime \prime}$ and $\tilde{\mathrm{B}}^{2} \mathrm{~A}^{\prime} \leftarrow \tilde{\mathrm{X}}^{2} \mathrm{~A}^{\prime \prime}$ transitions for comparison. Transitions 1 and 2 are $3 \mathrm{a}^{\prime \prime} \leftarrow 10 \mathrm{a}^{\prime}$ and $3 \mathrm{a}^{\prime \prime} \leftarrow 9 \mathrm{a}^{\prime}$ excitations and correspond to the $\tilde{\mathrm{A}}^{2} \mathrm{~A}^{\prime} \leftarrow \tilde{\mathrm{X}}^{2} \mathrm{~A}^{\prime \prime}$ and $\tilde{\mathrm{B}}^{2} \mathrm{~A}^{\prime} \leftarrow \tilde{\mathrm{X}}^{2} \mathrm{~A}^{\prime \prime}$ transitions, respectively.

In the photodissociation experiments in this study with $h v_{\text {diss }}$ between 5.17 and $5.96 \mathrm{eV}$, the ethoxy radical is excited to a higher-lying electronic state, for which the photofragment yield 
TABLE 2: Parameters Used in RRKM Rate Calculations, Obtained from B3LYP/6-311 ++ G $^{* *}$ Calculations $^{a}$

\begin{tabular}{|c|c|c|c|c|}
\hline & vibrational frequencies $\left(\mathrm{cm}^{-1}\right)$ & $A, B, C(\mathrm{GHz})$ & $I_{\text {red }}\left(\mathrm{amu} \AA^{2}\right)$ & $E_{0}(\mathrm{eV})$ \\
\hline $\mathrm{CH}_{3} \mathrm{CH}_{2} \mathrm{O}$ & $\begin{array}{l}118.7,266.0,434.9,866.0,885.7,1067.3,1096.2,1237.6,1334.2, \\
1387.8,1410.2,1484.5,1494.1,2885.8,2886.6,3029.3,3095.2, \\
3106.3\end{array}$ & $\begin{array}{l}39.641 \\
9.4820 \\
8.4479\end{array}$ & 2.806 & \\
\hline $\mathrm{TS}_{3}\left(\mathrm{CH}_{3}+\mathrm{CH}_{2} \mathrm{O}\right)$ & $\begin{array}{l}\text { 131.1, 268.3, 502.0, 540.4, 591.6, 897.0, 1102.1, 1239.0, 1409.3, } \\
1423.9,1482.4,1626.3,2896.4,2949.7,3090.1,3255.4,3268.2\end{array}$ & $\begin{array}{l}33.598 \\
8.2601 \\
7.2973\end{array}$ & 3.021 & 0.7466 \\
\hline $\mathrm{TS}_{4}\left(\mathrm{H}+\mathrm{CH}_{3} \mathrm{CHO}\right)$ & $\begin{array}{l}\text { 171.4, 384.6, 443.7, 503.3, 807.8, 901.4, 1096.9, 1126.1, 1375.6, } \\
1399.6,1462.8,1473.6,1687.4,2865.4,3021.3,3088.7,3134.0\end{array}$ & $\begin{array}{l}38.441 \\
9.5786, \\
8.7746\end{array}$ & 2.747 & 1.014 \\
\hline $\mathrm{TS}_{6}\left(\mathrm{CH}_{2} \mathrm{CH}_{2} \mathrm{O}\right)$ & $\begin{array}{l}374.9,715.6,821.0,918.1,971.6,1075.2,1079.2,1147.0,1207.9 \text {, } \\
1301.3,1427.6,1525.2,1917.5,3045.5,3093.7,3110.8,3220.7\end{array}$ & $\begin{array}{l}28.198 \\
13.047 \\
10.119\end{array}$ & & 1.331 \\
\hline
\end{tabular}

\footnotetext{
${ }^{a} I_{\text {red }}$ is the reduced moment of inertia for internal rotation about the $\mathrm{C}-\mathrm{C}$ bond. Vibrational frequencies are unscaled. $\mathrm{TS}_{i}$ refers to the transition state for the rate-limiting step for channel $i$.
}

(PFY) spectrum begins around $4.77 \mathrm{eV} .{ }^{25}$ The energy of transition 3, to the $\tilde{\mathrm{C}}^{2} \mathrm{~A}^{\prime \prime}$ state, predicted by TD-B3LYP (5.056 $\mathrm{eV}$ ) is a reasonable match with the onset of the PFY spectrum. This transition is predicted to have the highest oscillator strength, by far, of any of the transitions in this energy range, which also points to it as the most likely candidate for the experimental electronic transition, provided that we are exciting the ethoxy radical in its ground state rather than the low-lying $\tilde{\mathrm{A}}^{2} \mathrm{~A}^{\prime}$ state, which appears to be the case (see section IV. A). Transition 3 corresponds to an excitation from the $2 \mathrm{a}^{\prime \prime}$ orbital, a $\mathrm{C}-\mathrm{H} \sigma$ orbital for the $\mathrm{H}$ atoms lying outside the $\sigma_{\mathrm{s}}$ plane, to the $3 \mathrm{a}^{\prime \prime}$ orbital, the $\mathrm{O} \mathrm{p} \pi$ orbital outside the $\sigma_{\mathrm{s}}$ plane. We note, incidentally, that the calculated oscillator strength for the $\tilde{\mathrm{B}}^{2} \mathrm{~A}^{\prime}$ $\leftarrow \tilde{\mathrm{X}}^{2} \mathrm{~A}^{\prime \prime}$ transition is a factor of 20 lower than that for the $\tilde{\mathrm{C}}^{2} \mathrm{~A}^{\prime \prime}$ $\leftarrow \tilde{X}^{2} A^{\prime \prime}$ transition, which may account for the fact that the photofragment yield is lower by a factor of about 10 at 3.91 $\mathrm{eV}$ than at $5.17 \mathrm{eV}$.

A second set of calculations was carried out with the goal of determining the threshold for detachment to the $\tilde{\mathrm{A}}^{2} \mathrm{~A}^{\prime}$ electronic state of the $\mathrm{CH}_{3} \mathrm{CD}_{2} \mathrm{O}$ isotopomer. This threshold is known from experiment to be $1.756 \mathrm{eV}$ for $\mathrm{CH}_{3} \mathrm{CH}_{2} \mathrm{O}$ and $1.734 \mathrm{eV}$ for $\mathrm{CD}_{3} \mathrm{CD}_{2} \mathrm{O},{ }^{21}$ and isotopic substitution changes only the zeropoint energies. Therefore, we have approached this problem by first calculating the change in zero-point energy for detachment to the $\tilde{\mathrm{A}}^{2} \mathrm{~A}^{\prime}$ state of $\mathrm{CH}_{3} \mathrm{CH}_{2} \mathrm{O}$ and subtracting this value from the experimental value for the threshold for detachment to the $\tilde{\mathrm{A}}^{2} \mathrm{~A}^{\prime}$ state of $\mathrm{CH}_{3} \mathrm{CH}_{2} \mathrm{O}$ to find the non-zero-point-corrected detachment threshold. The same procedure was carried out for $\mathrm{CD}_{3} \mathrm{CD}_{2} \mathrm{O}$, and the two values were averaged. The calculated change in zero-point energy for $\mathrm{CH}_{3} \mathrm{CD}_{2} \mathrm{O}$ on detachment to the $\tilde{\mathrm{A}}^{2} \mathrm{~A}^{\prime}$ state was then added to this value to yield the detachment threshold. These calculations were carried out using the B3LYP method with the $6-311++\mathrm{G}^{* *}$ basis set, and the zero-point energies were scaled by the recommended factor of $0.9877 .{ }^{39}$

The calculated non-zero-point-corrected threshold for detachment to the $\tilde{\mathrm{A}}^{2} \mathrm{~A}^{\prime}$ state was $1.7018 \mathrm{eV}$ (the difference between the values calculated from data for the two isotopomers was $2.6 \mathrm{meV}$ ). We calculate the threshold for detachment to the $\tilde{\mathrm{A}}^{2} \mathrm{~A}^{\prime}$ state of $\mathrm{CH}_{3} \mathrm{CD}_{2} \mathrm{O}$ to be $1.743 \mathrm{eV}$, which is significantly higher than the lower detachment photon energy of $1.728 \mathrm{eV}$ used for this isotopomer.

Finally, we have employed electronic structure calculations to find the required parameters for RRKM rate calculations ${ }^{40}$ for reactions leading to the observed product channels, i.e., dissociation to $\mathrm{CH}_{3}+\mathrm{CH}_{2} \mathrm{O}$ and $\mathrm{H}+\mathrm{CH}_{3} \mathrm{CHO}$ and isomerization to $\mathrm{CH}_{2} \mathrm{CH}_{2} \mathrm{OH}$, which leads to $\mathrm{OH}+\mathrm{C}_{2} \mathrm{H}_{4}$. Parameters for the calculation of RRKM rate constants were determined using the B3LYP method and the $6-311++\mathrm{G}^{* *}$ basis set. The
TABLE 3: RRKM Dissociation Rate Constants $\left(\mathrm{s}^{-1}\right)^{a}$

\begin{tabular}{cccc}
\hline $\begin{array}{c}\text { excitation } \\
\text { energy }(\mathrm{eV})\end{array}$ & $k_{3}\left(\mathrm{CH}_{3}+\mathrm{CH}_{2} \mathrm{O}\right)$ & $k_{4}\left(\mathrm{H}+\mathrm{CH}_{3} \mathrm{CHO}\right)$ & $k_{6}\left(\mathrm{CH}_{2} \mathrm{CH}_{2} \mathrm{O}\right)$ \\
\hline 5.17 & $0.84 \times 10^{13}$ & $0.89 \times 10^{13}$ & $0.015 \times 10^{13}$ \\
5.64 & $0.99 \times 10^{13}$ & $1.1 \times 10^{13}$ & $0.020 \times 10^{13}$ \\
5.96 & $1.1 \times 10^{13}$ & $1.3 \times 10^{13}$ & $0.025 \times 10^{13}$
\end{tabular}

${ }^{a} k_{i}$ refers to the rate constant for channel $i$.

values of these parameters are shown in Table 2. We have used the recommended scale factors of 0.9679 for vibrational frequencies and 0.9877 for zero-point energies. ${ }^{39}$ There is a fair amount of variation in the calculated barrier heights for these reactions reported in the literature. The main difference between the barrier heights that we have determined and those reported by Hippler et al. ${ }^{6}$ (shown in Figure 1) which were calculated using QCISD(T) and the 6-311+G** basis set is that we calculate a somewhat higher (by $0.14 \mathrm{eV}$ ) barrier for the $\mathrm{H}+$ $\mathrm{CH}_{3} \mathrm{CHO}$ channel. However, we use our value for this barrier height for the sake of consistency.

The RRKM rate constants ${ }^{41}$ are given by

$$
k_{i}(E)=\frac{W_{i}(E)}{h \rho_{\text {Ethoxy }}(E)}
$$

where $W_{i}$ is the sum of states for transition state $i, \rho_{\text {Ethoxy }}$ is the density of states for the ethoxy radical, and $h$ is Planck's constant. We have treated the lowest vibrational frequency as an internal rotor in all but the transition state for isomerization to $\mathrm{CH}_{2} \mathrm{CH}_{2} \mathrm{OH}$. RRKM rate constants are shown in Table 3 .

\section{Discussion}

A. Initial Electronic State of Neutral Ethoxy before Excitation. In attempting to understand the results reported here, one would like to know which state of the ethoxy radical, the $\tilde{\mathrm{X}}^{2} \mathrm{~A}^{\prime \prime}$ ground state or the low-lying $\tilde{\mathrm{A}}^{2} \mathrm{~A}^{\prime}$ state, is present immediately before excitation by the photodissociation laser. The detachment photon energies used to acquire most of the data reported in this study were above the threshold for detachment to the $\tilde{\mathrm{A}}^{2} \mathrm{~A}^{\prime}$ state of ethoxy. It can be seen from Figure 6 that the photodissociation signal is much higher (by a factor of about 7) following detachment of $\mathrm{CH}_{3} \mathrm{CD}_{2} \mathrm{O}^{-}$at 1.771 $\mathrm{eV}$, above the threshold for the $\tilde{\mathrm{A}}^{2} \mathrm{~A}^{\prime}$ state, than at $1.728 \mathrm{eV}$, below the threshold. The higher signal reflects an increased photodetachment cross-section (determined in a separate experiment to be higher by a factor of roughly 5 at the higher detachment energy), which in turn is due to a combination of the increase in cross-section for detachment to the $\tilde{\mathrm{X}}^{2} \mathrm{~A}^{\prime \prime}$ state and the contribution from detachment to the $\tilde{\mathrm{A}}^{2} \mathrm{~A}^{\prime}$ state. 
TABLE 4: $\chi$, Angles (in degrees) between the Transition Dipoles, and the Recoil Vectors in the Short Time Limit, Approximated by the Angles between Transition Dipoles and Internuclear Axes Relevant to Dissociation, and $\beta_{0}=2 P_{2}(\cos$ $\chi)$, the Predicted Anisotropy Parameters in the Short-Time Limit for the $3 \mathrm{~A}^{\prime \prime} \leftarrow 2 \mathrm{~A}^{\prime \prime}$ Transition, Obtained from TD-B3LYP/6-311++** Calculations

\begin{tabular}{ccc}
\hline product channel & $\chi$ & $\beta_{0}$ \\
\hline $\mathrm{CH}_{3}+\mathrm{CH}_{2} \mathrm{O}$ & 65.4 & -0.482 \\
$\mathrm{OH}+\mathrm{C}_{2} \mathrm{H}_{4}$ & 1.43 & 2.00 \\
$\mathrm{H}+\mathrm{CH}_{3} \mathrm{CHO}$ & 72.3 & -0.721
\end{tabular}

The photodissociation results in Figure 6 show that $P\left(E_{\mathrm{T}}\right)$ and $\beta\left(E_{\mathrm{T}}\right)$ are essentially the same regardless of whether the photodetachment energy is above or below the threshold for the $\tilde{\mathrm{A}}^{2} \mathrm{~A}^{\prime}$ state. Dissociation following the $\tilde{\mathrm{C}}^{2} \mathrm{~A}^{\prime \prime} \leftarrow \tilde{\mathrm{A}}^{2} \mathrm{~A}^{\prime}$ transition would be expected to show different anisotropy parameters than dissociation following the $\tilde{\mathrm{C}}^{2} \mathrm{~A}^{\prime \prime} \leftarrow \tilde{\mathrm{X}}^{2} \mathrm{~A}^{\prime \prime}$ transition, since the transition dipole would be perpendicular to the $\sigma_{\mathrm{s}}$ plane in the ground-state equilibrium geometry, whereas the transition dipole for the $\tilde{\mathrm{C}}^{2} \mathrm{~A}^{\prime \prime} \leftarrow \tilde{\mathrm{X}}^{2} \mathrm{~A}^{\prime \prime}$ transition makes angles with the internuclear axes that are far from perpendicular (see Table 4 and discussion in section IV. B). While anisotropy parameters for photodissociation of polyatomic molecules can be unpredictable, it seems highly unlikely that nearly identical, nonzero anisotropy parameters would result from dissociation following these two transitions. Hence, the similarity of the dissociation dynamics for the two detachment energies in Figure 6 implies that, even for detachment above the excited-state threshold, the photodissociation signal is dominated by radicals which are in the $\tilde{\mathrm{X}}^{2} \mathrm{~A}^{\prime \prime}$ state at the time they are intercepted by the dissociation laser. Hence, either the fraction of the parent beam initially in the $\tilde{\mathrm{A}}^{2} \mathrm{~A}^{\prime}$ state is not very significant, it undergoes internal conversion before being intercepted by the dissociation laser beam and merely has slightly $(0.04 \mathrm{eV})$ more available energy, or it fails to photodissociate. Since, in addition, the ratio of data acquisition rates at 1.771 and $1.728 \mathrm{eV}$ is similar to the ratio of detachment efficiencies with detachment at these two energies, it is likely that little if any of the parent beam is in the $\tilde{\mathrm{A}}^{2} \mathrm{~A}^{\prime}$ state when it is intercepted by the dissociation laser.

B. Dissociation Mechanism. A central question with respect to the photodissociation mechanism of ethoxy is whether dissociation to all of the observed products takes place by internal conversion followed by dissociation on the ground-state surface or whether dissociation to one or more of the fragment pairs involves rearrangement and/or dissociation on the initially accessed excited-state surface. In assessing whether groundstate dissociation is the likely mechanism, an initial step is often to determine whether the observed product branching ratios, translational energy distributions, and anisotropy parameters are consistent with statistical ground-state dissociation, that is, with a mechanism in which the internal energy is statistically redistributed among the available modes before dissociation takes place.

Our results show that there are three major photodissociation channels for ethoxy: $\mathrm{CH}_{3}+\mathrm{CH}_{2} \mathrm{O}, \mathrm{OH}+\mathrm{C}_{2} \mathrm{H}_{4}$, and $\mathrm{H}+$ $\mathrm{CH}_{3} \mathrm{CHO}$. If all three channels occur on the ground state, then Figure 1 shows that $\mathrm{CH}_{3}$ and $\mathrm{H}$ atom loss occur via bond fission over small exit barriers (about 0.32 and $0.30 \mathrm{eV},{ }^{6}$ respectively) with respect to the products, whereas $\mathrm{OH}$ loss occurs by passage through the four-center transition state for isomerization to $\mathrm{CH}_{2} \mathrm{CH}_{2} \mathrm{OH}$.

We first consider the product branching ratios as a probe of the dissociation mechanism. Under the assumption of statistical dissociation on the ground state, the branching should be determined by relative values of rate constants calculated using RRKM theory at the bottleneck for each product channel. On the basis of Figure 1, we expect these bottlenecks to occur at the top of the exit barriers for $\mathrm{CH}_{3}$ and $\mathrm{H}$ loss and at the fourcenter isomerization transition state for $\mathrm{OH}$ loss. The results of our RRKM calculations, ${ }^{40}$ taking these bottlenecks as the critical configurations, are shown in Table 3. The branching fraction for $\mathrm{OH}$ loss predicted by these calculations is roughly 0.001 for all excitation energies, while $\mathrm{H}$ loss is slightly favored over $\mathrm{CH}_{3}$ loss. However, we find the branching fraction for the $\mathrm{OH}$ channel to be comparable to the other two, in direct contradiction to our RRKM results. Hence, the product branching ratios argue against statistical decay on the ground state.

We next consider the translational energy distributions. If a statistical model for dissociation is valid, then energy randomization occurs among all the internal degrees of freedom of the ethoxy radical prior to dissociation or isomerization. Under these circumstances, the $P\left(E_{\mathrm{T}}\right)$ distribution for a channel with little or no exit barrier peaks at or close to $E_{\mathrm{T}}=0,{ }^{41}$ while channels involving passage over an exit barrier can be described by a model in which the available energy in excess of the barrier is distributed statistically among the available modes, with the $P\left(E_{\mathrm{T}}\right)$ distribution peaking at some fraction of the barrier height. ${ }^{42,43}$

The $P\left(E_{\mathrm{T}}\right)$ distribution for the $\mathrm{CH}_{3}+\mathrm{CH}_{2} \mathrm{O}$ channel peaks close to $1.5 \mathrm{eV}$, a value almost five times the size of the exit barrier for this channel, and considerably larger than one would expect if statistical dynamics were operative. Similarly, the $\mathrm{H}$ $+\mathrm{CH}_{3} \mathrm{CHO}$ channel has a $P\left(E_{\mathrm{T}}\right)$ distribution peaking at about $1 \mathrm{eV}$, again larger than the exit barrier height for this channel. On the ground state, the $\mathrm{OH}$ channel could result from isomerization to $\mathrm{CH}_{2} \mathrm{CH}_{2} \mathrm{OH}$ followed by $\mathrm{OH}$ loss via the weakly bound $\mathrm{OH} \cdots \mathrm{C}_{2} \mathrm{H}_{4}$ complex, which, in a statistical picture, would result in a $P\left(E_{\mathrm{T}}\right)$ distribution peaking near $E_{\mathrm{T}}=$ 0 . It could also occur via direct dissociation from the four-center isomerization transition state without becoming trapped in the $\mathrm{CH}_{2} \mathrm{CH}_{2} \mathrm{OH}$ well, in which case more translational energy would be expected, since this transition state lies $0.23 \mathrm{eV}^{6}$ above the products. We find distributions peaking close to $0.5 \mathrm{eV}$ for this channel, again at variance (athough less so) with a statistical picture of dissociation.

Finally, we consider the photofragment angular distributions. From the results in Figures 5-8 and the accompanying discussion, the anisotropy parameter $\beta$ is positive for the $\mathrm{OH}$ $+\mathrm{C}_{2} \mathrm{H}_{4}$ channel, near 0.5 , while $\beta$ is zero or slightly negative for the $\mathrm{CH}_{3}+\mathrm{CH}_{2} \mathrm{O}$ channel and zero for $\mathrm{H}+\mathrm{CH}_{3} \mathrm{CHO}$. It is clear that, for all channels, $\beta$ lies quite far from its limiting values of 2 and -1 , representing parallel and perpendicular dissociation, respectively, with respect to the electric-field vector of the dissociation laser. These limiting values are found only when the time scale for dissociation is much faster than molecular rotation, as is found for direct dissociation on a repulsive excited-state surface, and the transition dipole of the molecule is aligned either parallel or perpendicular to the recoil axis of the fragments. On the other hand, dissociation of large molecules via internal conversion to the ground state generally yields isotropic angular distributions owing to long decay times with respect to molecular rotation. The ethoxy radical appears to be an intermediate case in that $\beta$ is small but definitely nonzero for at least one channel, so it is useful to consider what this result reveals about the dissociation mechanism.

Anisotropy parameters smaller than the limiting values of 2 and -1 can reflect any of several factors, including the geometry of the dissociating state and its lifetime compared to a typical 
rotational period. In Table 4 , the orientation of the transition dipole with respect to various bonds is given for transition 3 assuming the ground-state geometry of ethoxy. In this geometry, the transition dipole is nearly parallel to the $\mathrm{C}-\mathrm{O}$ bond. If we calculate $\chi$ for the $\mathrm{OH}+\mathrm{C}_{2} \mathrm{H}_{4}$ channel using the transitionstate geometry for $\mathrm{OH}$ loss calculated by Hippler ${ }^{6}$ and assuming that the $\mathrm{C}-\mathrm{O}$ bond in this geometry is parallel to the recoil direction, we calculate a value of 1.95 for $\beta_{0}$, the anisotropy parameter in the limit of instantaneous dissociation. Similar calculations yield $\beta_{0}=-0.69$ and -0.91 for $\mathrm{CH}_{3}$ and $\mathrm{H}$ atom loss, respectively. For all three channels, $|\beta|<\left|\beta_{0}\right|$, suggesting substantial rotation prior to dissociation, as one might expect for long-lived complex formation on the ground state. However, the consistently positive values for $\beta$ for $\mathrm{OH}$ loss are intriguing and raise the possibility that this channel, at least, may result from excited-state dissociation. Unfortunately, since the $\beta_{0}$ values are approximate and dynamic effects due to the conformational changes preceding dissociation may affect $\beta$ in ways that are difficult to predict, analysis of the angular distributions is not as definitive as one might hope in elucidating the dissociation mechanism.

To summarize the preceding discussion, none of the observables in this experiment support a photodissociation mechanism of internal conversion to the ground state followed by statistical decomposition. However, it is possible that dissociation does take place from the ground state, but at energies of roughly $4-5 \mathrm{eV}$ above the reaction barriers, dissociation is too fast for statistical redistribution of the excess energy among the available modes. Indeed, our RRKM calculations predict dissociation time constants on the order of 100 fs for $\mathrm{CH}_{3}$ and $\mathrm{H}$ loss, whereas timescales for vibrational relaxation on the order of $\sim 1$ ps have been observed in highly excited molecules prior to dissociation. ${ }^{44,45}$ If available energy is not statistically distributed, the $P\left(E_{\mathrm{T}}\right)$ distribution and product branching ratios might not closely resemble those predicted using statistical models.

One test of this possibility is to compare our results with those seen in studies of the $\mathrm{O}\left({ }^{3} \mathrm{P}\right)+\mathrm{C}_{2} \mathrm{H}_{5}$ reaction by Hoyermann et al. ${ }^{2}$ The internal energy of about $4 \mathrm{eV}$ in ethoxy obtained from this reaction is lower than the excitation energies in this study, but still far above the barriers for formation of any of the products that we have seen, thereby providing insight into ground-state dynamics with very high internal energy. Hoyermann et al. did find significant production of $\mathrm{OH}+\mathrm{C}_{2} \mathrm{H}_{4}$, along with $\mathrm{CH}_{3}+\mathrm{H}_{2} \mathrm{CO}$ and $\mathrm{H}+\mathrm{CH}_{3} \mathrm{CHO}$. However, since an inverted vibrational distribution had been found for $\mathrm{OH}$ formed in this reaction, ${ }^{19}$ they attributed this channel to direct bimolecular abstraction, rather than formation and subsequent isomerization of ethoxy to $\mathrm{CH}_{2} \mathrm{CH}_{2} \mathrm{OH}$ followed by dissociation. This conclusion, if correct, indicates that high internal energy on the ground state of ethoxy does not, by itself, lead to significant dissociation to $\mathrm{OH}+\mathrm{C}_{2} \mathrm{H}_{4}$. It should be noted, however, that chemical activation and photoexcitation would give different initial, nonstatistical distributions of energy in the ethoxy radical and might result in different branching fractions even if the amounts of excess energy were the same.

Since ground-state dissociation does not provide a clear explanation of the results, we next consider the possibility that internal conversion to the ground state is not the first step and the excited-state surface plays more of a role in dissociation for some or all of the product channels. The high branching ratio for the $\mathrm{OH}+\mathrm{C}_{2} \mathrm{H}_{4}$ channel is particularly difficult to explain in terms of ground-state dissociation. Since the transition to the excited state involves excitation of an electron out of the $\mathrm{C}-\mathrm{H} \sigma$ bonding orbital for the out-of-plane methyl $\mathrm{H}$ atoms, which are involved in the 1,3-hydrogen shift, and would lead to a weakening of these bonds, it is likely that the barrier for the four-center transition state on the excited-state surface is lower than that on the ground-state surface. Since, all else being equal, this would make the rate of isomerization more competitive, excited-state isomerization is a likely first step in dissociation for this channel. Further, the significantly nonzero anisotropy parameter for this channel is consistent with dissociation from the excited-state surface. Whether the 2-hydroxyethyl radical formed in this way undergoes dissociation on the groundor excited-state surface cannot be determined on the basis of our results.

Although it appears likely that formation of $\mathrm{OH}+\mathrm{C}_{2} \mathrm{H}_{4}$ involves isomerization on the excited-state surface, the mechanism by which the other two fragment pairs are formed is still not clear. It is reasonable, for example, to postulate a pathway involving one or more conical intersections that connect the excited state to the ground state, with those molecules that reach the ground state eventually dissociating to $\mathrm{H}+\mathrm{CH}_{3} \mathrm{CHO}$ and $\mathrm{CH}_{3}+\mathrm{CH}_{2} \mathrm{O}$. The observation that the relative yields of these two channels are close to those seen for dissociation on the ground-state surface following chemical activation ${ }^{2,4}$ is consistent with such a mechanism, in which case, the nonstatistical $P\left(E_{\mathrm{T}}\right)$ distributions for these channels would be attributed to dissociation that is too fast for full redistribution of vibrational energy to occur. However, excited-state dissociation cannot be ruled out for these two channels.

\section{Conclusions}

By employing a combination of coincidence and noncoincidence detection methods, we have studied the photodissociation dynamics of the ethoxy radical at energies from 5.17 to 5.96 $\mathrm{eV}$. On the basis of electronic structure calculations, the electronic transition excited in this region is assigned as the $3 \mathrm{a}^{\prime \prime} \leftarrow 2 \mathrm{a}^{\prime \prime}$ excitation to the $\tilde{\mathrm{C}}^{2} \mathrm{~A}^{\prime \prime}$ state. The product channels are $\mathrm{CH}_{3}+\mathrm{CH}_{2} \mathrm{O}, \mathrm{H}+\mathrm{CH}_{3} \mathrm{CHO}$, and $\mathrm{OH}+\mathrm{C}_{2} \mathrm{H}_{4}$, all in nearly equal yields. $\mathrm{CH}_{3}+\mathrm{CH}_{2} \mathrm{O}$ and $\mathrm{H}+\mathrm{CH}_{3} \mathrm{CHO}$ would be expected as major channels on the basis of the ground-state barriers to dissociation, but $\mathrm{OH}+\mathrm{C}_{2} \mathrm{H}_{4}$ would not be expected to contribute nearly as much as it does on this basis. On the basis of consideration of the product branching ratios, the fragment translational energy distributions, and the anisotropic angular distribution for the $\mathrm{OH}+\mathrm{C}_{2} \mathrm{H}_{4}$ channel, we conclude that statistical dissociation on the ground-state surface does not occur for any of the observed product channels and that isomerization to $\mathrm{CH}_{2} \mathrm{CH}_{2} \mathrm{OH}$ prior to $\mathrm{OH}$ loss probably occurs on an excited-state surface.

Acknowledgment. This work was supported by the Director, Office of Basic Energy Sciences, Chemical Sciences Division of the U. S. Department of Energy under contract no. DE AC0376SF00098. A.E.F. would like to thank Dr. John M. Herbert for useful discussions.

\section{References and Notes}

(1) Orlando, J. J.; Tyndall, G. S.; Wallington, T. J. Chem. Rev. 2003, $103,4657$.

(2) Hoyermann, K.; Olzmann, M.; Seeba, J.; Viskolcz, B. J. Phys. Chem. A 1999, 103, 5692.

(3) Reid, J. P.; Marcy, T. P.; Kuehn, S.; Leone, S. R. J. Chem. Phys. 2000, 113, 4572.

(4) Hack, W.; Hoyermann, K.; Olzmann, M.; Zeuch, T. Proc. Combust. Inst. 2003, 29, 1247. 7646.

(5) Yamada, T.; Bozzelli, J. W.; Lay, T. J. Phys. Chem. A 1999, 103,

(6) Hippler, H.; Viskolcz, B. Phys. Chem. Chem. Phys. 2000, 2, 3591 
(7) Somnitz, H.; Zellner, R. Phys. Chem. Chem. Phys. 2000, 2, 1907.

(8) Atkinson, R. Int. J. Chem. Kinet. 1997, 29, 99.

(9) Somnitz, H.; Zellner, R. Phys. Chem. Chem. Phys. 2000, 2, 1899.

(10) Piqueras, M. C.; Crespo, R.; Nebot-Gil, I.; Tomas, F. THEOCHEM 2001, 537, 199 .

(11) Zhang, X. B.; Liu, J. J.; Li, Z. S.; Liu, J. Y.; Sun, C. C. J. Phys. Chem. A 2002, 106, 3814.

(12) Hippler, H.; Viskolcz, B. Phys. Chem. Chem. Phys. 2002, 4, 4663.

(13) Liu, J. Y.; Li, Z. S.; Wu, J. Y.; Wei, Z. G.; Zhang, G.; Sun, C. C. J. Chem. Phys. 2003, 119, 7214.

(14) Zhang, Y.; Zhang, S. W.; Li, Q. S. Chem. Phys. 2004, 296, 79. 218.

(16) Zhang, Y.; Zhang, S. W.; Li, Q. S. Chem. Phys. 2005, 308, 109.

(17) Zhu, R. S.; Park, J.; Lin, M. C. Chem. Phys. Lett. 2005, 408, 25.

(18) Slagle, I. R.; Sarzynski, D.; Gutman, D.; Miller, J. A.; Melius, C. F. J. Chem. Soc., Faraday Trans. 2 1988, 84, 491.

(19) Lindner, J.; Loomis, R. A.; Klaassen, J. J.; Leone, S. R. J. Chem. Phys. 1998, 108, 1944.

(20) Foster, S. C.; Hsu, Y. C.; Damo, C. P.; Liu, X. M.; Kung, C. Y.; Miller, T. A. J. Phys. Chem. 1986, 90, 6766.

(21) Ramond, T. M.; Davico, G. E.; Schwartz, R. L.; Lineberger, W. C. J. Chem. Phys. 2000, 112, 1158.

(22) Inoue, G.; Okuda, M.; Akimoto, H. J. Chem. Phys. 1981, 75, 2060.

(23) Tan, X. Q.; Williamson, J. M.; Foster, S. C.; Miller, T. A. J. Phys. Chem. 1993, 97, 9311.

(24) Gopalakrishnan, S.; Zu, L.; Miller, T. A. Chem. Phys. Lett. 2003, $380,749$.

(25) Choi, H.; Bise, R. T.; Neumark, D. M. J. Phys. Chem. A 2000 , 104,10112 .

(26) Chase, M. W. Jr.; Davies, C. A.; Downey, J. R., Jr.; Fruip, D. J.; McDonald, R. A.; Syverud, A. N. JANAF Thermochemical Tables, 3rd ed. J. Phys. Chem. Ref. Data 1985, 14, Suppl. No. 1.

(27) Bauschlicher, C. W. J. Phys. Chem. 1994, 98, 2564.

(28) Lias, S. G.; Bartmess, J. E.; Liebman, J. F.; Holmes, J. L.; Levin, R. D.; Mallard, W. G. Gas-Phase Ion and Neutral Thermochemistry. J. Phys. Chem. Ref. Data 1985, 17, Suppl. No. 1

(29) Ellison, G. B.; Engelking, P. C.; Lineberger, W. C. J. Phys. Chem. 1982, 86, 4873 .

(30) Ervin, K. M.; Gronert, S.; Barlow, S. E.; Gilles, M. K.; Harrison, A. G.; Bierbaum, V. M.; Depuy, C. H.; Lineberger, W. C.; Ellison, G. B. J. Am. Chem. Soc. 1990, 112, 5750.

(31) Niiranen, J. T.; Gutman, D.; Krasnoperov, L. N. J. Phys. Chem. 1992, 96, 5881.
(32) Hoops, A. A.; Gascooke, J. R.; Faulhaber, A. E.; Kautzman, K. E.; Neumark, D. M. Chem. Phys. Lett. 2003, 374, 235.

(33) Continetti, R. E.; Cyr, D. R.; Osborn, D. L.; Leahy, D. J.; Neumark, D. M. J. Chem. Phys. 1993, 99, 2616.

(34) Osborn, D. L.; Leahy, D. J.; Cyr, D. R.; Neumark, D. M. J. Chem. Phys. 1996, 104, 5026.

(35) Osborn, D. L.; Choi, H.; Mordaunt, D. H.; Bise, R. T.; Neumark, D. M.; Rohlfing, C. M. J. Chem. Phys. 1997, 106, 3049.

(36) Cyr, D. R.; Continetti, R. E.; Metz, R. B.; Osborn, D. L.; Neumark, D. M. J. Chem. Phys. 1992, 97, 4937.

(37) Frisch, M. J.; Trucks, G. W.; Schlegel, H. B.; Scuseria, G. E.; Robb, M. A.; Cheeseman, J. R.; Montgomery, J., J. A.; Vreven, T.; Kudin, K. N.; Burant, J. C.; Millam, J. M.; Iyengar, S. S.; Tomasi, J.; Barone, V.; Mennucci, B.; Cossi, M.; Scalmani, G.; Rega, N.; Petersson, G. A.; Nakatsuji, H.; Hada, M.; Ehara, M.; Toyota, K.; Fukuda, R.; Hasegawa, J.; Ishida, M.; Nakajima, T.; Honda, Y.; Kitao, O.; Nakai, H.; Klene, M.; Li, X.; Knox, J. E.; Hratchian, H. P.; Cross, J. B.; Bakken, V.; Adamo, C. Jaramillo, J.; Gomperts, R.; Stratmann, R. E.; Yazyev, O.; Austin, A. J.; Cammi, R.; Pomelli, C.; Ochterski, J. W.; Ayala, P. Y.; Morokuma, K.; Voth, G. A.; Salvador, P.; Dannenberg, J. J.; Zakrzewski, V. G.; Dapprich, S.; Daniels, A. D.; Strain, M. C.; Farkas, O.; Malick, D. K.; Rabuck, A. D.; Raghavachari, K.; Foresman, J. B.; Ortiz, J. V.; Cui, Q.; Baboul, A. G.; Clifford, S.; Cioslowski, J.; Stefanov, B. B.; Liu, G.; Liashenko, A.; Piskorz, P.; Komaromi, I.; Martin, R. L.; Fox, D. J.; Keith, T.; Al-Laham, M. A.; Peng, C. Y.; Nanayakkara, A.; Challacombe, M.; Gill, P. M. W.; Johnson, B.; Chen, W.; Wong, M. W.; Gonzalez, C.; Pople, J. A. Gaussian 03, Revision C.02; Gaussian, Inc.: Wallingford, CT, 2004.

(38) Dreuw, A.; Weisman, J. L.; Head-Gordon, M. J. Chem. Phys. 2003 , 119,2943

(39) Andersson, M. P.; Uvdal, P. J. Phys. Chem. A 2005, 109, 2937.

(40) Hase, W. L.; Bunker, D. L. A General RRKM Program. QCPE 1974, 234.

(41) Baer, T.; Hase, W. L. Unimolecular Reaction Dynamics; Oxford University Press: Oxford, 1996.

(42) Mordaunt, D. H.; Osborn, D. L.; Neumark, D. M. J. Chem. Phys. 1998, 108, 2448.

(43) North, S. W.; Blank, D. A.; Gezelter, J. D.; Longfellow, C. A.; Lee, Y. T. J. Chem. Phys. 1994, 102, 4447.

(44) Meagher, J. F.; Chao, K. J.; Barker, J. R.; Rabinovitch, B. S. J. Phys. Chem. 1974, 78, 2535.

(45) Rynbrandt, J. D.; Rabinovitch, B. S. J. Phys. Chem. 1971, 75, 2164 